\title{
Programa Bolsa Família: proteção social e combate à pobreza no Brasil
}

Luciana Jaccoud

\section{Introdução}

Desde o final dos anos 1990, a temática da pobreza vem se impondo no Brasil e marcando de forma crescente a produção intelectual e o debate político. Contudo, foi principalmente no bojo das políticas públicas que a pobreza ganhou um espaço privilegiado. A emergência do Programa Bolsa Família (PBF) representou a afirmação de uma agenda nova no País, e seus resultados atestam a relevância dessa opção e da intervenção direta no âmbito da renda. Entretanto, no campo político e intelectual, muitas questões permanecem em aberto, seja em face do papel que o programa cumpre no conjunto da política social, seja no que se refere às perspectivas futuras da atuação social do Estado.

Este artigo se propõe a avançar algumas reflexões sobre o Programa Bolsa Família e seu objetivo de combate à pobreza, analisando-o como integrante do sistema brasileiro de proteção social (SBPS). A referência ao SBPS baliza um campo mais abrangente, para além do tradicionalmente utilizado para a análise 
do PBF. Nesse sentido, a perspectiva aqui adotada pretende, para além da reflexão sobre o programa e seu papel no combate à pobreza, observar a evolução do conjunto das políticas sociais organizadas na abordagem de proteção social, examinando-as a partir da criação e expansão do PBF.

A emergência de uma agenda da pobreza em toda a América Latina foi largamente influenciada pela disseminação, por grupos de interesse, comunidades epistêmicas e organismos internacionais, de um novo modelo de proteção social voltado ao enfrentamento à pobreza. Tendo como proposta principal os Programas de Transferência Condicionada de Renda (PTRC), e assentado no paradigma de desenvolvimento humano, a nova agenda propõe suprir as necessidades básicas por meio de transferências de renda e desenvolver capacidades por meio de condicionalidades em educação e saúde. Contudo, em que pese a perspectiva residualista que comandava a formulação de um projeto ancorado na priorização da pobreza, o processo de formatação e materialização destes programas nos diversos contextos nacionais está longe de consolidar experiênciashomogêneas. A emergência e implementação dos programas de transferência de renda para a população pobre respondeu a trajetórias institucionais e a contextos políticos diferenciados e se expressa em distintos resultados em termos do desenho dos programas e do papel que cumprem no campo da ação social do Estado e na própria dinâmica social.

No Brasil, o PBF encontrou uma adensada institucionalidade no campo social, que responde tanto aos desafios da garantia de renda quanto da ampliação da cobertura de serviços sociais ${ }^{1}$. Fruto da afirmação de direitos sociais universais reconhecidos pela Constituição de 1988 no contexto de redemocratização, o SBPS projeta a construção de uma cidadania social alargada e busca não apenas gerar acessos igualitários no campo das políticas sociais, como ampliar garantias de proteção social e reverter os patamares de desigualdade que esgaçam o tecido social brasileiro. Entretanto, ao mesmo tempo em que tem avançado expressivamente na efetivação de muitos de seus objetivos, o SBPS tem igualmente sido atravessado por tensões que se expressam tanto nas dificuldades de implementação (incluindo aqui os aspectos de financiamento, gestão e formas de participação do setor privado) quanto nos embates que cercam o projeto político que o acompanha.

O PBF desenvolveu-se, assim, em um contexto alargado de proteção social, e nele pode desempenhar um papel relevante. De um lado, ocupou campos que ainda se mantinham como de desproteção, tanto no que diz respeito à renda, como ao acesso a serviços. Nesse sentido, o PBF emergiu em um contexto de importante institucionalidade do SBPS e interagiu com ele, ampliando seu escopo protetivo. De outro lado, o programa ocupa uma posição que é cruzada por diferentes projetos de sociedade. Sua defesa mobiliza tanto os que defendem a ampliação da cobertura da proteção social pública, como os que criticam o projeto de universalização acolhido em 1988 e assentado em um modelo social redistributivo e altamente solidarista. São divergências que se referem aos princípios normativos da protecão social.

Buscando analisar esse processo, o sistema brasileiro de proteção social será examinado a partir da identificação de três distintas modalidades de intervenção, aqui chamadas de pilares da proteção social: garantia de renda, serviços universais e políticas para públicos específicos. Em cada um dos pilares, mas principalmente a partir 
da articulação e equilíbrio entre eles, a sociedade brasileira recoloca e responde à questão de com qual patamar de proteção (ou desproteção) social está operando e qual o patamar deverá ser operado em um horizonte futuro. Trata-se de um diálogo continuado sobre a capacidade de conviver com níveis (ainda) surpreendentes de desigualdades, e de responder às ameaças que a desigualdade aporta à coesão dessa sociedade. É nesse quadro que cabe abordar o tema do papel do Estado - enquanto representante da esfera pública - como promotor de padrões de coesão social.

Nos limites deste artigo, será priorizada a questão dos desafios postos ao desenho e institucionalidade das políticas sociais no contexto da nova agenda da pobreza. Nesse sentido, o PBF será analisado a partir do seu diálogo com o potencial de antagonismo e de conflito que a desigualdade social gera e os desafios que ela apresenta para a ação social do Estado. Nesta sua primeira década de existência, o PBF tem operado como um efetivo instrumento de alargamento da proteção social e de redução da desigualdade. São diversos os riscos de alteração deste quadro, tendo em vista as possibilidades e cenários postos pelos diferentes modelos de coesão social e desenvolvimento em concorrência no País. Mas é igualmente possível consolidar o PBF (e avançar no seu desenho) no contexto de uma cidadania social ampliada, nem limitada ao resgate da situação de pobreza nem à proteção ao mundo do trabalho, mas referente à promoção da igualdade e da equidade.

\section{O sistema de proteção social e o PBF}

Como já amplamente estudado, a proteção social brasileira se desenvolveu tendo por base o seguro social e excluindo, durante décadas, os grupos sociais sem vínculo com o mercado de trabalho formal ${ }^{2}$. A trajetória de limitada cobertura e de lento processo de expansão para os demais públicos foi revertida a partir da década de 1980 e, em especial, após a promulgação da Constituição de 1988, que lançou as bases para um novo formato da intervenção social do Estado. O texto constitucional alargou o arco dos direitos sociais e estendeu as garantias legais de

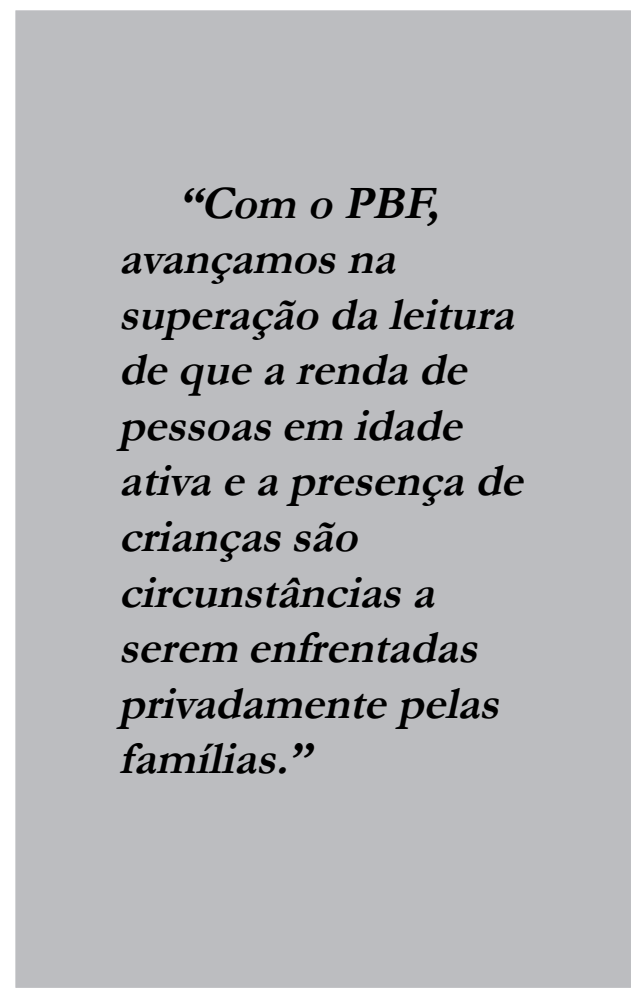

proteção a um conjunto mais amplo de situações sociais, expandindo o campo da proteção social sob responsabilidade estatal. Os objetivos da ação pública, regulamentada pelas leis complementares que normatizaram as determinações constitucionais, passaram a referir-se a um terreno vasto da vida social: desde o acesso a condições adequadas de bem-estar e 
oportunidades, como nas políticas de saúde e educação, até o enfrentamento dos riscos sociais e da pobreza, passando pela proteção ao ciclo de vida e as situações de desigualdade e discriminação.

Em resposta à orientação universalista e redistributivista acolhida pela Carta Constitucional de 1988, o esforço estatal na esfera da proteção social foi expressivamente ampliado, com impactos relevantes no que diz respeito ao desenho das políticas, à definição dos beneficiários e dos benefícios. As políticas sociais se adensaram, seja em termos normativos, seja em termos de recursos - humanos, financeiros, institucionais e políticos. As iniciativas e ofertas, largamente estruturadas em programas e políticas permanentes, formaram um conjunto que, embora heterogêneo, incompleto e algumas vezes contraditório, dotou o País de um sistema de proteção abrangente e de impacto efetivo. O adensamento da ação do Estado no campo social pode ser rapidamente vislumbrado por meio dos dados do gasto social, que aumentaram de maneira sustentada, crescendo cerca de 6,0 pontos percentuais do Produto Interno Bruto entre 1995 e 2010, e passando de $19,2 \%$ para $25,2 \%$ de um PIB em expansão (CAStro, 2013) ${ }^{3}$. As mais importantes políticas - regime geral da previdência social, saúde, educação e assistência social - contam com fortes arcabouços institucionais e fontes de financiamento estáveis, ainda que assentadas em uma estrutura tributária regressiva (Silveira et al., 2011).

Em face das amplas e diversas modalidades de intervenção do nosso Estado social, podem ser identificados três principais pilares em torno dos quais se vem organizando o atual sistema brasileiro de proteção social: garantia de renda, serviços universais e políticas para públicos específicos (JACCOUD, 2013). O primeiro opera benefícios monetários diretos, de natureza contributiva ou não contributiva, voltados a indivíduos ou a famílias. O segundo garante ofertas públicas e continuadas no campo dos serviços sociais, com destaque para os sistemas nacionais na educação, saúde e assistência social. Por fim, no âmbito do enfrentamento de desigualdades associadas a públicos específicos, atua por meio de políticas públicas inovadoras ou de recortes diferenciados nas já existentes, visando a atender e integrar grupos que enfrentam processos de discriminação e segregação constrangedores de direitos e de oportunidades de inclusão social.

Reorganizado a partir da Constituição de 1988 e fortalecido posteriormente, o pilar de garantia de renda assegura benefícios previdenciários e assistenciais ${ }^{4}$. Os benefícios previdenciários, de natureza contributiva e organizados na forma de seguro social público e obrigatório, visam a proteger as situações de inatividade, sejam elas temporárias (como as relacionadas à doença e maternidade $)^{5}$ ou definitivas (velhice, invalidez ou morte). Os programas assistenciais, não contributivos e integralmente financiados com recursos tributários, dirigem-se às situações de pobreza. $\mathrm{O}$ Benefício de Prestação Continuada (BPC), benefício assistencial regulamentado em 1993, visa à proteção dos segmentos marcados pela inatividade: idosos com 65 anos e pessoas com deficiência em situação de extrema pobreza ${ }^{6}$. Esse benefício também opera com a garantia de uma renda de substituição àqueles impossibilitados (e) ou desobrigados) de garantir sua sobrevivência pelo próprio trabalho, mas garante o acesso pela comprovação da situação de pobreza e não de contribuição ou trabalho.

O caráter solidário e redistributivo do sistema também foi ampliado com a 
flexibilização da lógica atuarial do modelo previdenciário, representada pela criação da figura do segurado especial rural ${ }^{7}$. Com esses benefícios, o sistema de garantia de renda no Brasil praticamente universalizou sua cobertura para idosos. Como consequência, os dados de 2002 e 2012 da Pnad mostram que, em 2002, ou seja, antes da implementação do PBF, apenas 1,4\% dos idosos brasileiros de 60 anos ou mais estavam em situação de extrema pobreza, e apenas 7,4\% em situação de pobreza (em 2012 esses percentuais baixaram para 1,0\% e $1,4 \%$ respectivamente).

A criação do PBF, em 2003, ampliou e reforçou o sistema de garantia de renda. Como já destacado em trabalhos anteriores (JACCOUd, 2009 e 2010), a grande inovação do PBF refere-se à superação de um modelo limitado da proteção às situações de inatividade com oferta de uma renda de substituição. O PBF opera um avanço na reponsabilidade pública, estendendo a garantia de renda para além das situações de não trabalho. Efetiva um benefício de renda mínima às famílias pobres cujos membros adultos estão majoritariamente em idade laboral ativa e participando do mercado de trabalho ${ }^{8}$. Por outro lado, como já destacado por Mesquita et al. (2010), a cobertura às famílias pobres também responde à inexistência, no sistema brasileiro de proteção social, de um benefício voltado às crianças? .

Assim, os programas previdenciários e assistenciais do sistema de garantia de renda, apesar de distintos quanto à natureza da proteção e o público coberto, vêm operando em dinâmica relativamente integrada em face do duplo desafio: a manutenção de renda (prevenindo o risco da pobreza) e o enfrentamento da pobreza já instalada. A evolução do PBF não desencadeou restrições na cobertura dos demais programas; ao contrário, sua implementação ao longo da última década foi acompanhada pela ampliação da cobertura previdenciária e do BPC. Segundo os boletins da Previdência Social e do MDS, uma estimativa dos benefícios concedidos, em dezembro de 2012, pelos programas contributivos e não contributivos de garantia de renda vigentes no Brasil, aponta para um total de 43,9 milhões de benefícios, com impacto efetivo nos patamares de pobreza e desigualdade de renda. Desses, 26,03 milhões foram de natureza previdenciária (RGPS). O BPC pagou naquele mês 3,99 milhões de benefícios destinados a idosos e pessoas com deficiência pobres. Foram ainda concedidos 13,9 milhões de benefícios para famílias pobres por meio do Bolsa Família $^{10}$. O adensamento e o caráter redistributivo da proteção social, atestados em um amplo conjunto de estudos ${ }^{11}$, refletem a ampliação da cobertura, a relativização do princípio atuarial, a vinculação do piso do BPC e RGPS ao salário mínimo e o fortalecimento da solidariedade como princípio organizador da cobertura e do financiamento.

Com o PBF, avançamos na superação da leitura de que a renda de pessoas em idade ativa e a presença de crianças são circunstâncias a serem enfrentadas privadamente pelas famílias. Avançamos ainda no reconhecimento de uma renda mínima, com impactos muito relevantes. Esta garantia foi fortalecida em 2013, quando o mecanismo tradicional do PBF, de benefícios com valores fixos em função da profundidade da pobreza (se com renda até $R \$ 70,00$ ou até $R \$ 140,00$ ) e da composição da família, foi complementado, permitindo a adoção de um novo compromisso em face de um mínimo social per capita, ainda inexistente no Brasil. A criação do novo benefício variável do PBF 
(Benefício de Superação da Extrema Pobreza), visando a cobrir o hiato de renda de até $\mathrm{R} \$ 70,00$, instituiu um patamar mínimo de renda abaixo do qual nenhum brasileiro pode estar.

No que se refere ao segundo pilar, de oferta de serviços universais, o SBPS opera um conjunto de ofertas continuadas com o objetivo de garantir, fora do mercado, patamares de bem-estar, cuidados e aquisições, além de estabelecer acesso desmercadorizado a bens públicos e culturais, conhecimentos e ativos construídos pela sociedade. Opera ainda com a responsabilização coletiva de riscos individuais - em especial na saúde, mas também na assistência social e na educação. Tais ofertas têm progredido quanto à universalização do acesso. Entretanto, são expressivas as dificuldades diante dos objetivos de se contrapor à reprodução das desigualdades sociais, efetivar igualdade de chances e fortalecer um projeto de integração e desenvolvimento social. São dificuldades particularmente graves quando referidas a alguns públicos específicos, como é o caso dos mais pobres ou as populações negras.

A integração do PBF a esse pilar do SBPS realiza-se principalmente por meio das condicionalidades em educação e saúde, que devem ser cumpridas pelas famílias atendidas. Sua adoção foi bastante contestada, mobilizando preocupações quanto à focalização das políticas universais. Contudo, o aprimoramento da gestão intersetorial para o controle e acompanhamento das condicionalidades, assim como a progressiva presença do Sistema Único de Assistência Social (SUAS) têm permitido que essas se afirmem não como tarefa burocrática ou punitiva, mas como instrumento de inclusão, naquelas políticas, de populações em denegação de acesso $^{12}$.
De fato, entre os expressivos desafios enfrentados no âmbito da oferta de serviços públicos, destaca-se o da inclusão e permanência da população mais pobre. São vários os motivos que dificultam a equalização do atendimento para esses segmentos: desde as características da população e seus territórios, até mecanismos de segregação e expulsão operados no interior das políticas públicas. Em que pesem as dificuldades, os resultados dessa estratégia têm sido relevantes, como mostram os estudos sobre os impactos das condicionalidades na trajetória escolar - positivos tanto na frequência quanto na progressão dos alunos - e nas condições nutricionais e de saúde das crianças ${ }^{13}$.

Cabe destacar que a interface entre o PBF e os serviços da assistência social também têm sido objeto de um conjunto recente de estudos que descortinam os diversos matizes dessa integração: o papel dos Centros de Referência da Assistência Social (CRAS) no suporte ao Cadastro Único e a gestão dos benefícios do PBF e no diálogo e acompanhamento da população beneficiária, além dos arranjos intitucionais visando à gestão local, ao controle social e à articulação e coordenação federativa ${ }^{14}$. Efetivamente, o desenvolvimento simultâneo da implementação e universalização do PBF e a institucionalização e consolidação do SUAS a partir de 2003 e 2004, respectivamente, possibilitaram uma forte interação (não imune a tensões) entre os dois processos. A consolidação da política pública de assistência social, ancorada em um sistema único de escopo nacional, operada em equipamentos públicos e por equipes de referência, e contando com serviços permanentes em substituição às ações eventuais e descontinuadas, permite novos patamares de proteção para situações agravadas de vulnerabilidade social ${ }^{15}$. 
A integração do PBF com as ofertas de educação, saúde e assistência social vem se consolidando como um caminho promissor, capaz não apenas de prevenir e/ou resgatar trajetórias de vulnerabilidade social, mas de fortalecer, nos territórios, a oferta pública e sua efetividade nessas três áreas. O PBF vem atuando nos serviços de educação e saúde, mas também da assistência, como um vetor de priorização do público de menor renda, enfrentando lógicas restritivas de oferta e acesso que perpassam, inclusive, o setor público. A dificuldade de acesso e permanência nos serviços, demonstrada por um grande conjunto de indicadores sociais, persiste como um problema cuja densidade é grave para os grupos mais pobres, em que pese esse tema ainda não estar sendo amplamente problematizado no debate acadêmico e institucional sobre as políticas setoriais.

Dessa forma, o tema da focalização do PBF também deve ser abordado a partir da perspectiva mais abrangente do contexto institucional e do desenho de proteção social no qual o programa se insere. Se para a perspectiva residualista a priorização aos mais pobres representa a centralidade no papel projetado para as políticas sociais, do ponto de vista do fortalecimento de um sistema público universal voltado à redução das desigualdades, tal prioridade contribui para fortalecer o acesso universal, inclusive para os mais pobres. E de fato, o PBF tem sido progressivamente fortalecido para operar como um instrumento de promoção da equidade. Dialoga, assim, com o pilar do SBPS voltado ao enfrentamento de desigualdades associadas a públicos específicos, submetidos a processos de apartação, discriminação, segregação ou tratamento diferenciado que constrangem direitos e oportunidades.
Trata-se, nesse terceiro grupo de políticas públicas, tanto de operar com programas ou políticas públicas específicas, como de atuar visando ao tensionamento e à integração das políticas existentes para atender àqueles grupos. Muitas vezes o processo histórico de discriminação e subalternidade social efetua a "invisibilidade" de determinados públicos ou demandas, dificultando a atuação do Estado e questionando a legitimidade da ação pública

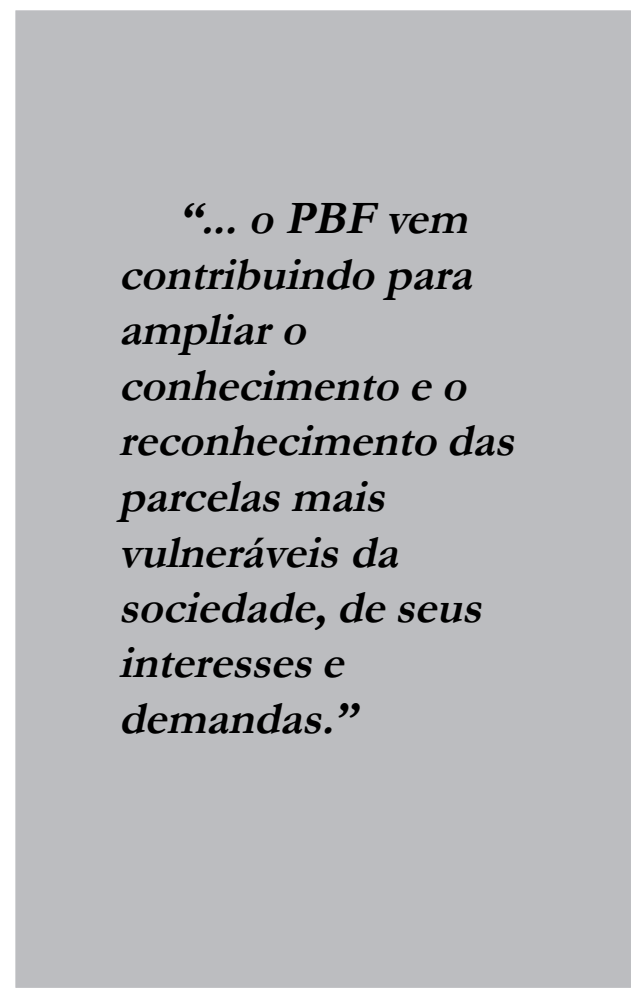

nesse plano. Nesse sentido, os desafios ainda são muito expressivos, em que pese os avanços observados nas ações voltadas à extrema pobreza ou à população negra. A ampliação do investimento (não apenas financeiro, mas em recursos humanos e institucionais) dos três níveis de governo, assim como o desenho de estratégias mais adensadas para enfrentar os expressivos 
padrões de desigualdade da sociedade brasileira - e seus mecanismos de reprodução - permanece imperativo.

\section{Programa Bolsa Família e trabalho}

Compreender a especificidade da proteção de renda realizada pelo Bolsa Família implica ultrapassar a imprecisão operada por meio do termo 'pobres' e buscar identificar as dinâmicas da vulnerabilidade que afetam o seu público-alvo. Destaca-se, para além da alta presença de crianças e da mais fraca aderência às políticas públicas, a precariedade da inserção no mundo do trabalho. Como já citado, o PBF inaugurou a proteção às famílias pobres com larga presença de membros adultos em idade ativa. Participantes do mercado de trabalho, os chefes de famílias beneficiárias apresentam nível de atividade, ocupação e jornada bastante similares aos dos não beneficiários (Sagi/MDS, 2012). Contudo, sua participação no mercado de trabalho ocorre em bases mais precárias, com taxas mais elevadas de desemprego e de trabalho sem remuneração. Sobre o comportamento dos beneficiários do PBF no mercado de trabalho, os estudos existentes apontam a inexistência de qualquer impacto no sentido de desestímulo à participação - o chamado "efeito preguiça" (Oliveira e SoArEs, 2012 e 2013).

Para além da análise das características e comportamento dos beneficiários, as pesquisas e estudos têm avançado mais lentamente. É relevante destacar que as situações de pobreza associam-se a territórios e populações, atividades e dinâmicas econômicas, além de características de oferta de serviços e políticas públicas. Referem-se a contextos históricos - populações tradicionais e população negra - ou familiares específicos. Reproduzem-se em regiões estagnadas ou em setores ou atividades econômicas de baixa (ou em queda de) produtividade. A pobreza se reproduz largamente junto à agricultura familiar constrangida pela falta de insumos, financiamento, apoio técnico, mercado ou mesmo terras. Da mesma forma ocorre em territórios urbanos segregados, com altas taxas de violência e baixa oferta de serviços públicos, incluindo transporte, educação e serviços vinculados à inclusão no mercado de trabalho. Nesse sentido, políticas públicas voltadas à promoção das condições de inclusão produtiva, como o Programa Nacional de Acesso ao Ensino Técnico e Emprego (Pronatec) ou o Programa de Aquisição de Alimentos (PAA), revestemse de grande relevância e devem continuar a ser fortalecidas. Políticas setoriais de fomento da produção e do emprego, visando à promoção de um projeto de desenvolvimento com equidade, são essenciais, e seus resultados revelam-se incapazes de serem criados pela dinâmica autônoma dos mercados (Delgado e Theodoro, 2005).

Contudo, além das consequências na esfera da ação pública, a interface entre trabalho e PBF também deve ser melhor analisada pelo que tem a nos esclarecer sobre as bases políticas do sistema de proteção social. Ao atender um público cuja vulnerabilidade se vincula predominantemente à idade e à situação de possibilidade de trabalho, o PBF não apenas inova, mas igualmente provoca uma tensão no âmbito do SBPS ${ }^{16}$. De um lado - e como todo o debate sobre pobreza e pauperismo vem nos ensinando desde o século XIX -, a pobreza questiona a premissa básica dos sistemas econômicos no capitalismo de transformarem trabalho em bem-estar (Polany, 2000). De outro, garantir uma renda às famílias cuja população adulta está 
apta para o trabalho questiona a centralidade do trabalho, que organiza as sociedades contemporâneas. Essas dificuldades somam-se aos desafios de consolidação do campo da assistência social e às resistências à legitimação da natureza solidária e não contributiva de sua intervenção. Como lembra Morel (2000), no caso da assistência social, a ausência de reciprocidade entre os beneficiários e os que financiam seus benefícios tensiona a esfera da proteção social. Tais problemas reduzem-se quando os beneficiários formam o grupo daqueles chamados por Castel (1998) como os "inaptos ao trabalho": idosos, crianças ou deficientes. Mas se adensam quando se trata de benefícios dirigidos à população em condições de exercício do trabalho. A demanda por contrapartidas busca, em larga medida, compensar tais dificuldades de legitimação, particularmente fortes em sociedades altamente produtivistas e cujos assentos individualizadores se fazem cada vez mais presentes (CASTEL, 2009).

No caso brasileiro, onde a dinâmica produtiva não promoveu a larga primazia do processo de assalariamento das relações de trabalho, e onde as desigualdades no mercado de trabalho reproduzem um sistema hierárquico que ainda alimenta e organiza largamente a sociedade, as dificuldades se agravam. A alegação de desvio moral (preguiça, irresponsabilidade, indolência) no comportamento dos beneficiários fortalece o questionamento em torno do PBF e de sua legitimidade, assim como de demandas das chamadas "portas de saída" ${ }^{17}$. De fato, a suspeita contra os segmentos de trabalhadores pobres não integrados às relações formais de trabalho é um elemento permanente do debate social brasileiro. Por outro lado, o acesso ao trabalho em suas várias dimensões da oferta e da demanda ainda é uma dimensão desafiadora para as políticas públicas e para a dinâmica de crescimento da economia brasileira.

Vale lembrar algumas características gerais da população com renda compatível à da linha de acesso ao PBF. Segundo dados da Pnad 2012 ${ }^{18}$, encontramos na população economicamente ativa (PEA), com renda menor que $\mathrm{R} \$ 140,00$, percentual considerável de trabalhadores (40\%) ocupados em atividades de produção para consumo próprio $(25,5 \%)$ ou em atividades sem remuneração (13,5\%). Encontramos ainda $29 \%$ dedicados a trabalho por conta, 19\% empregados sem carteira assinada e $8 \%$ dedicados ao emprego doméstico. Nesse contexto de trabalho precário e renda incerta, os desafios são expressivos e sinalizam para a necessidade de adensamento das chamadas políticas ativas de mercado de trabalho (Kerstenetzky, 2012). A questão racial também se apresenta com força nesse contexto. A maior presença de pretos e pardos entre os extratos de menor renda reflete e reproduz a inclusão subalterna dessa população, aspecto central nos mecanismos de reprodução da desigualdade social no País (Theodoro, 2008). Cabe ainda lembrar a relevância da questão de gênero na análise da inserção da população mais pobre no mercado de trabalho. Cruzam-se aqui, entre as mais pobres, menores taxas de atividade, relacionadas não apenas a menores ofertas de serviços de cuidados para a primeira infância, mas a outras questões como a contribuição diferenciada do trabalho na esfera doméstica e as condições específicas da monoparentalidade.

Nesse sentido, o PBF vem contribuindo para ampliar o conhecimento e o reconhecimento das parcelas mais vulneráveis da sociedade, de seus interesses e demandas. Para além dos avanços a ele 
creditados na melhoria das condições de vida e de acesso às políticas públicas, o programa tem ainda atuado no alargamento da autonomia e da cidadania (Rego e PizAni, 2013). Tem igualmente favorecido novas iniciativas, inclusive no campo da melhoria das condições de acesso ao mercado de trabalho, como as operadas por meio do plano Brasil sem Miséria, nos seus eixos rural e urbano, visando a uma maior e mais qualificada oferta de políticas e oportunidades (FOnSECA et al., 2013).

\section{Conclusão: igualdade e equidade no SBPS}

O debate sobre como articular os princípios de igualdade e equidade nas políticas sociais brasileiras atravessa a discussão em torno do PBF e das perspectivas futuras do SBPS. Na trilha aberta pelas críticas ao desenho universalista das políticas sociais brasileiras, a equidade tem-se sobressaído, defendida como princípio não apenas relevante, mas suficiente - de justiça visando à igualdade. São diversos os riscos colocados por essa formulação, tendo em vista o alto patamar de desigualdade que organiza a sociedade brasileira. A equidade adotada sem referência à igualdade fragiliza as condições de integração social, agravando um tecido de sociabilidade já esgaçado pela profunda desigualdade que ainda marca o País.

De fato, a crítica liberal ao universalismo, ancorada na ideia da igualdade de chances, pouco fala sobre os patamares de desigualdade aceitáveis (RosanvaLLon, 2011). A sociologia nos ensina que o desafio da desigualdade não se restringe às questões de justiça associadas às trajetórias individuais, mas as ultrapassa, marcando a dinâmica social como um todo. Maior igualdade impacta a qualidade das relações sociais e o patamar de bem-estar. E, como mostrou Castel (1988), mesmo quando atingindo apenas as franjas da vida social, a pobreza e a vulnerabilidade questionam a sociedade em seu conjunto, apontando para o risco de sua fratura e mobilizando o debate em torno dos princípios e mecanismos de sua coesão.

Desse modo, se a existência da desigualdade no Brasil impõe a adoção de políticas públicas ancoradas no princípio da equidade, ela não aceita o descarte ou a subordinação do princípio da igualdade no processo de implementação de políticas públicas (JACCOUD, 2013). Ao contrário, reenfatizando o princípio da igualdade como base da ação pública, e o combate à desigualdade como objeto estratégico de uma agenda de futuro, é que as ações voltadas à equidade podem operar como instrumentos relevantes num projeto inclusivo e redistributivo de desenvolvimento social.

A progressiva expansão do $\mathrm{PBF}$ ao longo dos últimos anos vem sendo realizada de forma integrada às demais políticas do SBPS. O programa tem cumprido um papel específico e complementar aos demais programas de renda, beneficiando uma população distinta e não atendida pelos benefícios pré-existentes. Também no campo dos serviços, o PBF vem sendo implementado em um contexto de forte institucionalidade, o que permite que venha apresentando impactos positivos no que se refere à inclusão e à permanência dos grupos e populações mais pobres nas políticas de saúde, educação e assistência social. Como parte do SBPS, o PBF pode comemorar 10 anos como uma peça importante no âmbito da complexa construção voltada à proteção social no Brasil. Por fim, ao provocar o debate em torno da pobreza, o PBF tem contribuído para o 
aprofundamento e a qualificação das ações diante do compromisso social em torno do seu enfrentamento.

Contudo, os altos níveis de desigualdade com que convive - e a partir dos quais se organiza historicamente - a sociedade brasileira impõem a continuidade da trajetória de redução da pobreza e da promoção da igualdade. O progresso em face desses objetivos dependerá do aprofundamento das políticas sociais, tendo por horizonte o enfrentamento das desigualdades. Para além da sustentação da política de valorização do salário mínimo (inclusive devido às repercussões de sua vinculação aos benefícios monetários da seguridade social) e dos impactos positivos advindos do mercado de trabalho, a efetividade desse caminho é largamente dependente de decisões políticas em prol da equidade e do fortalecimento das ofertas universais de qualidade.

Nesse sentido, é preciso superar definitivamente as formulações que limitam o debate sobre a pobreza, reduzindo-o simplesmente a um debate sobre o outro. Para além das situações vividas por famílias ou populações específicas, de constrangimentos no acesso a bens, serviços, oportunidades e proteção social, a pobreza e a desigualdade refletem uma dinâmica social marcada por enorme diferenciação e mesmo apartações. Para uma sociedade menos desigual é necessário superar os riscos de dualização da proteção social risco mais amplo, de que as políticas sociais findem por reforçar hierarquias sociais pela própria operacionalização da oferta pública. A continuidade no processo de integração do PBF ao SBPS e de fortalecimento das políticas universais e de qualidade responde não apenas à demanda de dotar de dignidade e perspectiva de futuro os mais vulneráveis. Responde à busca de uma dinâmica social inclusiva, que não apenas favorece a um ambiente economicamente mais dinâmico, mas, sobretudo, socialmente melhor compartilhado.

(Artigo convidado).

\section{Notas}

${ }^{1} \mathrm{O}$ sistema de proteção social e, dentro dele, o de seguridade social, não apenas desenvolveram uma ampla regulamentação e institucionalização, como têm contado com expressiva legitimidade social (ver pesquisa coordenada por Lavinas, 2013). O respaldo político ao modelo de proteção social acolhido em 1988 é um dos fatores que explicam as dificuldades dos governos liberais da década de 1990 de implementarem suas reformas.

${ }^{2}$ Podem ser citados, entre outros, Malloy, James. Politica de Previdência Social no Brasil. Rio de Janeiro, Graal, 1986; SANTos, Wanderley Guilherme. Cidadania e Justiça : a política social na ordem brasileira. Rio de Janeiro: Campos, 1987; Draibe e Aureliano. A especificidade do Welfare State brasileiro. In: Economia e Desenvolvimento, n.3, Cepal, Brasília, 1989 ; Oliveira e Fleury TeIXeIra. In : Previdência Social : 60 anos de história da previdência no Brasil. Rio de Janeiro: Vozes/ABPGSC, 1995. 
${ }^{3}$ Analisando apenas o gasto social federal entre 1995 e 2010, Castro et al. (2012) revelam que: (i) em termos real e per capita, o gasto social federal mais que dobrou no período; (ii) o crescimento foi observado em todo o período, mas houve uma aceleração mais nítida após 2004; (iii) os ganhos reais foram observados em todas as áreas.

${ }^{4}$ Para uma análise mais detalhada do sistema de garantia de renda - benefícios, beneficiários e impactos -, assim como do PBF e sua relação com demais benefícios monetários, ver Mesquita et al. (2010).

${ }^{5}$ Além dos benefícios previdenciários, cabe lembrar do seguro-desemprego, voltado à proteção das situações de desemprego involuntário.

${ }^{6} \mathrm{O}$ acesso ao BPC independe de quaisquer contribuições prévias; o valor do benefício é de um salário mínimo, tendo sido definido pela própria Constituição Federal.

${ }^{7}$ A categoria de segurados especiais estabelecida pela CF-88 integra os trabalhadores rurais em regime de economia familiar ao RGPS, aos quais reconhece os mesmos benefícios dos trabalhadores urbanos formais, à exceção da forma de contribuição. Tal inovação ancora o direito à previdência social no exercício pretérito do trabalho - ainda que não assalariado - e não mais exclusivamente na vinculação prévia a um emprego com carteira assinada ou a um certo número de contribuições efetivadas.

${ }^{8}$ Cabe lembrar que o PBF não atende apenas a famílias com crianças. As famílias com renda abaixo da linha de extrema pobreza $(\mathrm{R} \$ 70,00)$ têm acesso ao benefício básico e ao benefício de superação da extrema pobreza independentemente da composição da família. Cerca de $12 \%$ das famílias beneficiárias não têm crianças e estão abaixo da linha de extrema pobreza; sobre elas não operam as condicionalidades. Sobre os benefícios do PBF, ver: http://www.mds.gov.br/ bolsafamilia/beneficios.

${ }^{9}$ No Brasil, a escassa cobertura do salário-família e o parco reconhecimento da isenção para dependentes operada no Imposto de Renda de Pessoas Físicas como uma ação governamental de natureza social, dificultam o desenvolvimento de um benefício familiar. É expressivo o número de países que reconhece a existência de crianças como um risco adicional de empobrecimento dos trabalhadores e de suas famílias, risco que deve ser protegido. Em geral, as deduções fiscais para dependentes também são computadas entre os esforços sociais do governo em benefício das famílias.

${ }^{10}$ Quase metade (46\%) desses 43,9 milhões de benefícios são no valor de um salário mínimo e $33 \%$ em valor inferior a um salário mínimo. Cabe ainda lembrar que não foram computados os benefícios do seguro-desemprego, concedido a mais de 8 milhões de trabalhadores desempregados por períodos entre 3 a 5 meses.

${ }^{11}$ Entre 2003 e 2011, os percentuais de extrema pobreza foram reduzidos à metade (Ipea, 2012). Sobre o impacto dos programas de garantia de renda na redução da pobreza e desigualdade de renda, ver, por exemplo, Soares et al. (2010); Ipea (2012); Sagi/MDS (2013); Castro (2013).

${ }^{12}$ De acordo com a Portaria no 251/2012 do MDS, nenhuma família terá o benefício cancelado sem que antes seja acompanhada pelo poder público. Esse acompanhamento deve ser realizado pelos Centros de Referência da Assistência Social (CRAS) dos municípios, e permite a interrupção dos efeitos do descumprimento sobre o benefício, a identificação das situações que dificultaram o acesso aos serviços básicos de educação e de saúde e os encaminhamentos e atividades necessários para sua superação.

${ }^{13}$ Sobre educação, ver em especial Simões (2013); Craveiro e Ximenes (2013); Cireno et al. (2013) e Silvera et al. (2013); sobre saúde, ver entre outros Raselle et al. (2013); Santos et al. (2013). 
${ }^{14}$ Ver a respeito Bichir (2011); Lício (2012); Colin et al. (2013); Coutinho (2013); Silva Neto (2013); Arsky (2013).

${ }^{15}$ Sobre a evolução do SUAS, ver os capítulos sobre a assistência social no boletim "Políticas Sociais: acompanhamento e análise", publicado semestralmente pelo Ipea.

${ }^{16}$ São retomados aqui os argumentos desenvolvidos em Jaccoud (2009).

${ }^{17}$ No entanto, é interessante observar que o PBF conta com o apoio majoritário da população: 73\% segundo pesquisa realizada em 2012 (LAVINAS, 2012). Segundo a pesquisa, a maioria da população $(59 \%)$ aceitaria pagar mais impostos para garantir a provisão pública de educação e saúde, e que considera educação, saúde e creche bens públicos e universais. Contudo, 68\% apoiam totalmente as condicionalidades atuais do PBF e 56\% concordam com adoção de condicionalidades vinculadas ao trabalho.

${ }^{18}$ A tabulação considerou a renda per capita domiciliar: estão incluídas todas as rendas na sua composição, inclusive as advindas do PBF.

\section{Referências bibliográficas}

Arsky, Daniela. A integração do Programa Bolsa Familia e da Assistência Social - um olhar sobre a gestão municipal do Programa. Monografia apresentada no curso de especialização em Gestão Pública - 8ª Edição. ENAP, Brasília, outubro de 2013.

BICHIR, Renata. Mecanismos federais de coordenação de politicas sociais e capacidades institucionais locais: o caso do Programa Bolsa Família. 2011. Tese (doutorado). Instituto de Estudos Sociais e Políticos. Universidade do Estado do Rio de Janeiro.

Castel, Robert. As metamorfoses da questão social. Petrópolis/RJ: Vozes, 1998. . La Montée des incertitudes: travail, protections, statut de l'individu. Paris, Ed

Seuil, 2009.

Castro, Jorge. Política social, distribuição de renda e crescimento econômico. In: Fonseca, Ana e Fagnani, Eduardo (Orgs). Políticas Sociais, cidadania e desenvolvimento. Editora Fundação Perseu Abramo, Coleção Projetos para o Brasil, 2013.

CAstro, Jorge et al. Gasto Social Federal: prioridade macroeconômica no período 1995 2010. Ipea, Brasília, Nota técnica nº 9, 2012.

Cireno, Flávio; Silva, Joana; Proença, Rafael. Condicionalidades, desempenho e percurso escolar de beneficiários do Programa Bolsa Família. In: Campello, Tereza e Neri, Marcelo (Orgs). Programa Bolsa Família: uma década de inclusão e cidadania. Brasília: Ipea, 2013. p. 297-304.

Colin, Denise; Pereira, Juliana; Goneldi, Valéria. Trajetória de construção da gestão integrada do Sistema Único de Assistência Social, do Cadastro Único e do Programa Bolsa Família para a consolidação do modelo brasileiro de proteção social. In: CAMPELLO, Tereza e Neri, Marcelo (Orgs). Programa Bolsa Família: uma década de inclusão e cidadania. Brasília: Ipea, 2013. p. 47-64. 
Coutinho, Diogo. Capacidades estatais no Programa Bolsa Família: o desafio de consolidação do Sistema Único de Assistência Social. Brasília, IPEA, Texto para Discussão n ${ }^{\circ}$ 1852, 2013.

Craveiro, Clélia; Ximenes, Daniel. Dez anos do Programa Bolsa Família: desafios e perspectivas para a universalização da Educação Básica no Brasil. In: CAmPELlo, Tereza e Neri, Marcelo (Orgs). Programa Bolsa Família: uma década de inclusão e cidadania. Brasília: Ipea, 2013. p. 109-124.

Delgado, Guilherme ; Theodoro, Mário. Desenvolvimento e Política Social. In: JACCoud, L. (Org.). Questão social e políticas sociais no Brasil contemporâneo. Brasília: Ipea, 2005. p. 409-435 Fonseca, Ana; Jaccoud, Luciana; Karam, Ricardo. Do Bolsa Família ao Brasil sem Miséria. In: Fonseca, Ana e Fagnani, Eduardo (Orgs). Políticas Sociais, cidadania e desenvol vimento. Editora Fundação Perseu Abramo, Coleção Projetos para o Brasil, v. 2, 2013.

IBGE. Pesquisa Nacional por Amostra de Domicílios - Pnad 2002 - Síntese de indicadores. Rio de Janeiro: IBGE, 2003.

. Pesquisa Nacional por Amostra de Domicílios - Pnad 2012 - Síntese de indicadores. Rio de Janeiro: IBGE, 2013.

IPEA. A Década Inclusiva (20012011): Desigualdade, Pobreza e Políticas de Renda. Brasília, Comunicados do Ipea n 155, setembro de 2012.

Jaccoud, Luciana. Pobres, pobreza e cidadania: os desafios recentes da proteção social. Brasília: IPEA. Capítulo da Série Seguridade Social - Texto para discussão n 1372, 2009.

O PBF e o combate a pobreza: reconfigurando a proteção social no Brasil? In: Castro, Jorge e Modesto, Lúcia (orgs). Bolsa Família 2003 2010: avanços e desafio. Brasília: IPEA-MDS, 2010. v. 1, p. 101-136.

. Igualdade e equidade na agenda da proteção social. In: FonseCA, Ana e

Fagnani, Eduardo (orgs). Políticas Sociais, cidadania e desenvolvimento. Editora Fundação Perseu Abramo. Coleção Projetos para o Brasil, v. 2, 2013.

Kerstenetzky, Celia. O estado do bem estar social na idade da razão. Rio de Janeiro: Ed. Elsevier/Campus, 2012.

Lavinas, Lena (coordenadora). Medindo o grau de aversão à desigualdade da população brasileira. Rio de Janeiro, UFRJ, Relatório de pesquisa, novembro de 2012.

Lício, Elaine. Para além da recentralização: os caminhos da coordenação federativa do Programa Bolsa Família (2003-2010). 2012. Tese de doutorado. Instituto de Serviço Social. Universidade de Brasília.

Mesquita, Ana Cleusa; Jaccoud, Luciana; Santos, Maria Paula. Perspectivas para o Sistema de Garantia de Renda no Brasil. In: IPEA, Perspectivas da Politica Social no Brasil. Brasília: IPEA, 2010. p. 345-418.

Morel, Sylvie - Les logiques de la reciprocité, les transformations de la relation d'assistance aux Etats Unis et en France. Paris : PUF, 2000.

Oliveira, Luis; SOARES, Sergei. O que se sabe sobre os efeitos das transferências de renda sobre a oferta de trabalho. Brasília, Ipea, Textos para Discussão nº 1738, 2012.

. "Efeito Preguiça”" em programa de transferência de renda? In: CAMPELLO, Tereza e Neri, Marcelo (Orgs). Programa Bolsa Família: uma década de inclusão e cidadania. Brasília: Ipea, 2013. p. 341-358. 
Polanyi, Karl. A Grande Transformação: as origens da nossa época. 9. ed. Rio de Janeiro: Editora. Campus, 2000.

Rasella, Davide et al. Efeitos do Programa Bolsa Família sobre a mortalidade em crianças: uma análise nos municípios brasileiros. In: Campello, Tereza e Neri, Marcelo (Orgs.). Programa Bolsa Família: uma década de inclusão e cidadania. Brasília: Ipea, 2013. p. 247-262.

RêGo, Walquíria; Pinzani, Alessandro. Vozes do Bolsa Família: autonomia, dinheiro e cidadania. São Paulo: Editora Unesp, 2013.

Rosanvallon, Pierre. La société des égaux. Paris: Editora Seuil, 2011.

SAGI/MDS. Efeitos do Programa Bolsa Família (PBF) sobre a desigualdade e a extrema pobreza: análise e evidências a partir do Censo Demográfico 2010. Brasília: MDS-SAGI. Estudo Técnico no 14/2013.

. Bolsa Familia e seus impactos nas condições de vida da população brasileira: principais resultados da pesquisa Avaliação de Impacto do Bolsa Família II. Brasília: MDS - SAGI. Estudo Técnico nº 03/2012.

SANTOS, Leonor et al. Menor ocorrência de baixo peso ao nascer entre crianças de famílias beneficiárias do Programa Bolsa Família. In: Campello, Tereza e Neri, Marcelo (Orgs). Programa Bolsa Família: uma década de inclusão e cidadania. Brasília: Ipea, 2013. p. 263-272. Silva Neto, Pedro Eduardo. O Programa Bolsa Família e o Índice de Gestão Descentralizada como agentes indutores da estruturação da Rede da Assistência Social no Brasil. 2013. Monografia apresentada no curso de especialização em Política Públicas de Proteção e Desenvolvimento Social - 2 Edição. ENAP: Brasília, outubro de 2013.

Silveira, Fernando et al. Qual o impacto da Tributação e dos Gastos Públicos Sociais na distribuição de renda do Brasil? Observando os dois lados da moeda. In: Progressividade da tributação e desoneração da folha de pagamentos: elementos para reflexão. Brasília: Ipea, Sindifisco: Dieese, 2011.

Silveira, Fernando; Campolina, Bernardo; Horn, Ross. Impactos do Programa Bolsa Família na alocação do tempo entre escola e trabalho de crianças e adolescentes de 10 a 18 anos. In: Campello, Tereza e Neri, Marcelo (Orgs). Programa Bolsa Família: uma década de inclusão e cidadania. Brasilia: Ipea, 2013. p. 305-326.

SIMÕES, Armando. Os Jovens que não estudam nem trabalham no Brasile o Bolsa Família. Brasília: MDS/SAGI. Estudo Técnico no 15/2013.

SoAres, S.; SouZA, P.; Osório, R.; Silveira, F. (2010) Os impactos do benefício do Programa Bolsa Família sobre a desigualdade e a pobreza. In: CAstro, Jorge e Modesto, Lúcia (Orgs). Bolsa Famila 2003 2010: avanços e desafio. Brasília: IPEA-MDS, 2010. v. 2, p. 25-52.

Theodoro, Mário (Org.). As políticas públicas e a desigualdade racial no Brasil: 120 anos após a abolição. Brasília: IPEA, 2008. 


\section{Resumo - Resumen - Abstract}

\section{Programa Bolsa Família: proteção social e combate à pobreza no Brasil}

Luciana Jaccoud

A emergência da temática da pobreza e a disseminação dos programas de transferência condicionada de renda na América Latina foram largamente influenciadas por uma leitura residualista de proteção social, assentada no paradigma do desenvolvimento humano e no fortalecimento da responsabilidade individual em face das demandas de proteção social. Contudo, o processo de implementação consolidou desenhos distintos de programas, respondendo a trajetórias institucionais e a cenários políticos diferenciados. No Brasil, o Programa Bolsa Família foi implementado num contexto de adensada institucionalidade no campo social, tanto no que se refere à garantia de renda como aos serviços de educação e saúde. $\mathrm{O}$ artigo analisa o processo de implementação e progressiva universalização do PBF a partir de sua inserção no sistema brasileiro de proteção social e sua integração a programas e políticas, discutindo ainda tensões e dificuldades cujo enfrentamento permitirá avançar a agenda de enfrentamento à pobreza e à desigualdade social.

Palavras chave: Bolsa Família; proteção social; equidade

\section{Programa Bolsa Familia: protección social y combate a la pobreza en Brasil} Luciana Jaccoud

La emergencia de la temática de la pobreza y la diseminación de los programas de transferencia condicionada de renta en América Latina fueron ampliamente influidas por una lectura residualista de protección social, asentada en el paradigma del desarrollo humano y en el fortalecimiento de la responsabilidad individual frente a las demandas de protección social. Sin embargo, el proceso de implementación consolidó diseños distintos de programas, en respuesta a las trayectorias institucionales y a los escenarios políticos diferenciados. En Brasil, el Programa Bolsa Familia se implementó en un contexto de adensada institucionalidad en el campo social, tanto en lo que se refiere a la garantía de renta como a los servicios de educación y salud. En el artículo se analiza el proceso de implementación y universalización progresiva del PBF a partir de su inserción en el sistema brasileño de protección social y su integración a los programas y políticas, y se discute todavía tensiones y dificultades cuyo enfrentamiento permitirá el avance de la agenda de enfrentamiento a la pobreza y a la desigualdad social.

Palabras clave: Programa Bolsa Familia; protección social; equidad

\section{The Bolsa Família Program: social protection and reduction of poverty in Brazil}

\section{Luciana Jaccoud}

The emergence of the theme of poverty in the academic debate and the dissemination of income transfer programs in Latin America were largely influenced by a focal understanding of social protection, which rested on the paradigm of human development. Nevertheless, such programs were implemented in different ways, since they were influenced by different institutional paths and political scenarios. In Brazil, the Bolsa Família Program was implemented in a highly institutionalized social area, with the existence of both income transfer policies and public services of health and education. This paper analyzes the implementation process of the Bolsa 
Família Program and its progressive universalization since its insertion in the Brazilian social protection system, addressing the challenges associated with the Program.

Keywords: Bolsa Família Program; social protection; social equity

Luciana Jaccoud

É doutora em sociologia pela École des Hautes Études en Sciences Sociales (França) e exerce o cargo de assessora especial do Ministério do Desenvolvimento Social e Combate à Fome (MDS). Contato: luciana.jaccoud@mds.gov.br 